\title{
Effectiveness of Cognitive Behaviour Therapy in the Management of Anxiety among School Students
}

\author{
Veena Chakravarthy ${ }^{1}$, Dr. V. Chandramohan ${ }^{2}$
}

\section{ABSTRACT:}

Anxiety is a feeling of uneasiness characterized by irritability, palpitations, dry mouth, tension and a feeling of impending doom. Anxiety feels like "fear"; one might know what one is afraid of, but it is difficult to know what makes one anxious. Anxiety impairs academic performance. The aim of the present study is to find out effectiveness of Cognitive behaviour therapy in the management of anxiety among school students. One hundred thirty healthy and well motivated school students, sixty five Boys and sixty five girls, studying Higher Secondary Course at Cambridge Matriculation and Higher Secondary School, Bangalore, constituted as a sample for the present study. School students were administered with 16 Personality Factor Questionnaire Form D (16 PF) to assess anxiety in their basic personality. Out of 130 school students, 50 students, twenty five Boys and twenty five Girls, who showed high anxiety in the assessment of personality (16 PF), were administered with State Trait Anxiety Index (STAI) to assess the magnitude and severity of anxiety. Fifty School students, who were identified as anxiety prone in the personality test, showed high anxiety on STAI. They were managed through Cognitive behaviour therapy (CBT) to counteract ill-effects of anxiety for three months. Results clearly indicate that there is extremely significant difference $(\mathrm{P}>0.0001)$ existing between pre and post test Trait anxiety Percentile Rank scores of school students. CBT helped in the management of anxiety among school students. CBT seems to be one of the most effective, less time consuming and more economical therapeutic techniques in the management of anxiety among school students.

Keywords: Cognitive behaviour therapy, anxiety, school students

Anxiety is a feeling of uneasiness characterized by irritability, palpitations, dry mouth, tension and a feeling of impending doom. Anxiety feels like "fear"; one might know what one is afraid of, but it is difficult to know what makes one anxious. Usually anxiety is caused due to stress. Anxiety manifests itself in several other ways like forgetfulness, aggression, low self esteem, lack of confidence and eating disorders.

1Research Scholar, Department: Psychology, Bharathiar University, Coimbatore 2Research Supervisor, Reader in Psychology, Institute of Aerospace Medicine, IAF, Vimanapura (PO), Bangalore 
Anxiety is a trait found in personality and is commonly referred to as Neuroticism or emotional instability or poor stress tolerance. Anxiety is a psychological and physiological state characterized by cognitive, somatic, emotional, and behavioral components. These combine to create an unpleasant feeling that is typically associated with uneasiness, fear or worry (Seligman, et al., 2001).

The general symptoms of anxiety are feeling of threat, excessive worry, tremor, twitchy sensations and nervousness, aching and sore muscles, restlessness, sleeping difficulties, inability to concentrate and irritability. Other symptoms to identify anxiety include intestinal distress, frequent urination, trouble swallowing, lump in the throat, over sensitivity in interpersonal relationship, difficulty in decision making, depression, vague apprehensions and fears. The common signs of acute anxiety are feelings of fear or dread, restlessness, trembling, muscle tension, rapid heartbeat, light headedness or dizziness, perspiration, cold hands / feet and shortness of breath (Christensen, 2006 ; Rosen and Schulkin, 1998)..

Chandramohan et al., (1998) utilised Cognitive behaviour therapy for the management of airsickness and fear of flying among ab-initio pilot trainees. 100\% success rate was achieved through Cognitive behaviour therapy.

A minimal amount of anxiety is essential for good academic performance. Once it exceeds the limit, it impairs the academic performance. Hence, the present study was undertaken to find out an effective therapeutic technique for the management of anxiety among school students.

\section{AIM}

The aim of the present study was to find out effectiveness of Cognitive behaviour therapy in the management of anxiety among school students.

\section{OBJECTIVE}

The main objective of the present study was to identify and prevent ill effects if anxiety among school students thereby academic performance can be improved. Tension free life brings healthy living not only as a student but also as a good professional. It reduces attrition rate among school students.

\section{MATERIALS AND METHOD}

One hundred thirty healthy and well motivated students, sixty five Boys and sixty five girls, age ranging from 15 to 18 years, studying Higher Secondary Course at Cambridge Matriculation and Higher Secondary School, Bangalore, constituted as a sample for the present study. School students were administered with 16 Personality Factor Questionnaire Form - "D" (16 PF) to assess anxiety in their basic personality. Short detail of Psychological tests is given below:

16 PERSONALITY FACTOR QUESTIONNAIRE - FORM "D” (16 PF) - Cattell (1970) has developed $16 \mathrm{PF}$ to assess basic personality structure of an individual. $16 \mathrm{PF}$ is a well known 
objectively scoreable factorial test of personality. $16 \mathrm{PF}$ is multi dimensional set of sixteen questionnaire scale arranged in an omnibus form. It is comprehensive in coverage and give information regarding an individual's standing on sixteen Primary Factors and eight Second Order Factors. Cattell has developed different forms of 16 PF and they are Form 'A', 'B', 'C', ' $D$ ' and ' $E$ '. The Computerised version of 16 PF has been developed by Chandramohan (1991), at Institute of Aerospace Medicine, IAF, Bangalore, is used for analysing the responses. On obtaining the STEN score, an individual's relating standing in each of the factor is expressed on a Profile Chart. The STEN score positions for each factor are distributed over ten equal interval STEN points (Standard Score Points) from 1 through 10, with the population average fixed at 5.5 and standard deviation at1. 16 PF test - Form " $D$ " is used in the present study. This test has got 105 statements. There is no right or wrong answers. Answer as honestly as possible to give the first response coming into your mind. Three boxes are given on the answer sheet to record the responses. Students are asked to choose one answer out of 3 choices, by putting, a " $\sqrt{ }$ " mark inside the box. Here, A - True or Yes, B - Sometimes, In between, Occasionally, Uncertain, C False or No. Try to avoid choosing 'B' as an answer because it does not reflect any qualities. It usually takes 30 minutes to complete.

Scoring: Each answer is awarded with marks 0,1 and 2. Whereas, for Factor B, the scores are 0 (incorrect) or 1 (Correct). The total score constitute the raw score for that particular trait. The raw score is further converted into Standard (STEN) score, using norms supplied by the author. The STEN scores are reflected on the Profile Chart to see the individual's relative standing on the 16 Primary Traits. The Second Order Factors are calculated from the scores of Primary Factors. The 8 Second Order factors are, as follows:

$\begin{array}{llll}\text { Factor I } & - & \text { ANXIETY } & \text { - Low Vs High Anxiety } \\ \text { Factor II } & - & \text { EXTRAVERSION } & \text { - Introversion Vs Extraversion } \\ \text { Factor III } & - & \text { TOUGH POISE } & \text { - Emotional Sensitivity Vs Alert poise } \\ \text { Factor IV } & - & \text { INDEPENDENCE } & \text { - Subduedness Vs Independence } \\ \text { Factor V } & - & \text { SUPEREGO/CONTROL } & \text { - Low Control Vs High Control } \\ \text { Factor VI } & - & \text { ADJUSTMENT } & \text { - Neuroticism Vs Adjustment } \\ \text { Factor VII } & - & \text { LEADERSHIP } & \text { - Low Leadership Vs High Leadership } \\ \text { Factor VIII } & - & \text { CREATIVITY } & \text { - Low Creativity Vs High Creativity }\end{array}$

Md (Motivational distortion score) - STEN score above 7, the test is invalid

Significance level of STEN score on Primary Factors

STEN $1-3=$ Low score

STEN $4-6=$ Average

STEN $8-10=$ High score

Significance level of STEN score on Second Order Factors

STEN $1-4=$ Low score 
STEN $5-6=$ Average

STEN $7-10=$ High score

STEN score 4 and 7 shows tendency towards that particular trait

Out of 130 school students, 50 students, twenty Boys and twenty five Girls, who were high on anxiety in the personality test (Table 1), constituted as a sample for the final study.

Table 1: Sample Characteristics

\begin{tabular}{|c|c|c|}
\hline \multirow{2}{*}{ PARAMETER } & \multicolumn{2}{|c|}{ HIGH ANXIETY ON 16 PF TEST } \\
\cline { 2 - 3 } & NUMBER & $\%$ \\
\hline BOYS & 25 & 17 \\
\hline GIRLS & 25 & 17 \\
\hline
\end{tabular}

Table I showed Sample characteristics. Out of one hundred and thirty school students, 25 Boys (17\%) and 25 Girls (17\%) were high on anxiety in the 16 PF test. Hence, the sample taken for the present study was a homogenous sample.

Table 2 : Mean Pretest Percentile rank of STAI

\begin{tabular}{|c|c|c|c|c|}
\hline \multirow{2}{*}{ PARAMETER } & \multicolumn{2}{|c|}{ STATE ANXIETY } & \multicolumn{2}{c|}{ TRAIT ANXIETY } \\
\cline { 2 - 5 } & MEAN & SD & MEAN & SD \\
\hline Boys $(\mathrm{n}=65)$ & 52 & 27 & 45 & 21 \\
\hline Girls $(\mathrm{n}=65)$ & 44 & 18 & 42 & 25 \\
\hline
\end{tabular}

Table 2 showed mean Pretest Percentile Rank of the school students. It was evident from the Table that boys were high on State anxiety but low on Trait anxiety. On the other hand, both the Boys and Girls were low on State and Trait anxiety.

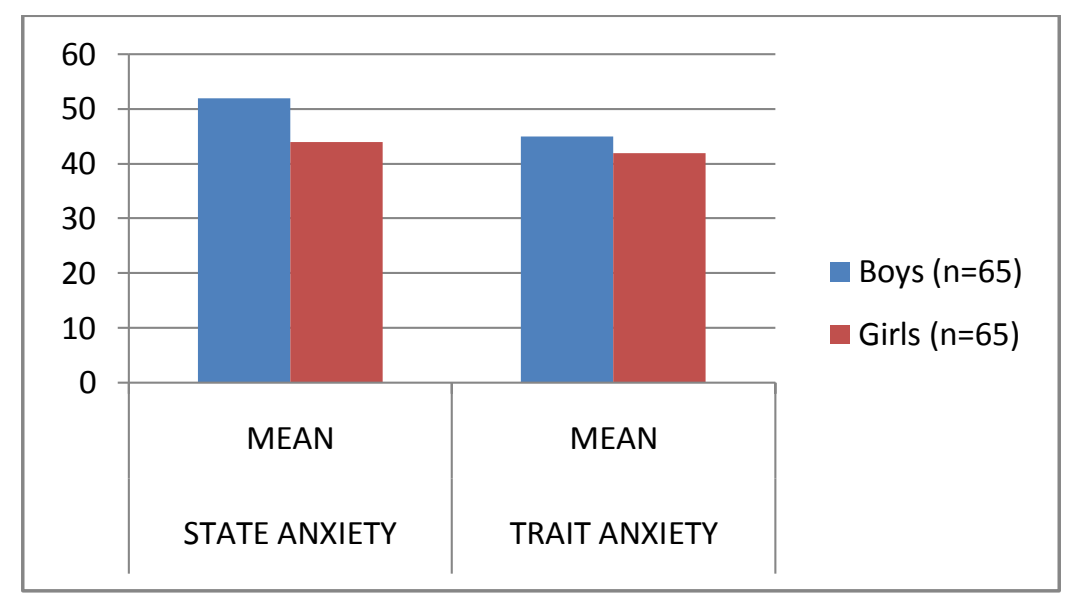

Figure 1: Mean Pretest and Posttest Percentile rank of STAI 
Out of 130 students, only 25 Boys and 25 Girls were high on anxiety. The remaining students were free from anxiety. These fifty school students were exposed to CBT, once in a day on an empty stomach, five days in a week for three months, CBT included Modified Jacobson's Progressive muscular Relaxation therapy (Kaliappan and Murthy (1978), Bensons Relaxation therapy and Mental Imagery (imagining natural sceneries such as seaside appealing beach, parks, waterfalls) and psychological way of studying was explained (attached as Annexure).

Cognitive behaviour therapy group was administered with State Trait Anxiety Index (STAI) before (Pretest) and after three months (Posttest) of continuous treatment to assess the magnitude and severity of anxiety (Table 3).

Short detail of Psychological tests is given below:

STATE TRAIT ANXIETY INDEX (STAI): Spielberger (1979) has developed to assess level of anxiety. STAI - State Anxiety is transitional, situational and also called as surface anxiety. For example, fear of examination, medical examination of the patient, facing the interview. On the other hand, STAI - Trait Anxiety is inborn, inherited and also called as source anxiety. Norms are available for high school and college students, medical and psychiatric patients, young prison inmates and normal adults, males and females separately. STAI consists of 20 statements in each. In the STAI - State Scale, the subject is asked to rate his / her immediate feelings (how he / she feels at that particular moment?. In the STAI - Trait Scale, the subject is asked to rate his/ her feelings for the past 2 years. Record all your answers on a separate answer sheet. Do not make any marking on the questionnaire. It usually takes 10 minutes to finish each scale.

Scoring: Standard scoring procedure adopted. Lower the percentile rank, the less nervous and anxious person you are; the higher your score, the more nervous and anxious a person you are.

\section{FINDINGS AND DISCUSSIONS}

The findings of the present study were discussed on Table 3 Figure 2.

Table 3: Mean Pre and Posttest Percentile rank of Trait Anxiety of the treatment group

\begin{tabular}{|c|c|c|c|c|c|c|}
\hline \multirow[t]{2}{*}{ PARAMETER } & \multicolumn{2}{|c|}{ PRE TEST } & \multicolumn{2}{|c|}{ POST TEST } & "t" - & LEVEL OF \\
\hline & MEAN & SD & MEAN & SD & \multirow[b]{2}{*}{31.99} & \multirow[b]{2}{*}{$\mathrm{P}>0.0001$} \\
\hline Boys $(n=25)$ & 68 & 6 & 9 & 7 & & \\
\hline Girls $(n=25)$ & 65 & 5 & 2 & 1 & 61.77 & $\mathrm{P}>0.0001$ \\
\hline
\end{tabular}




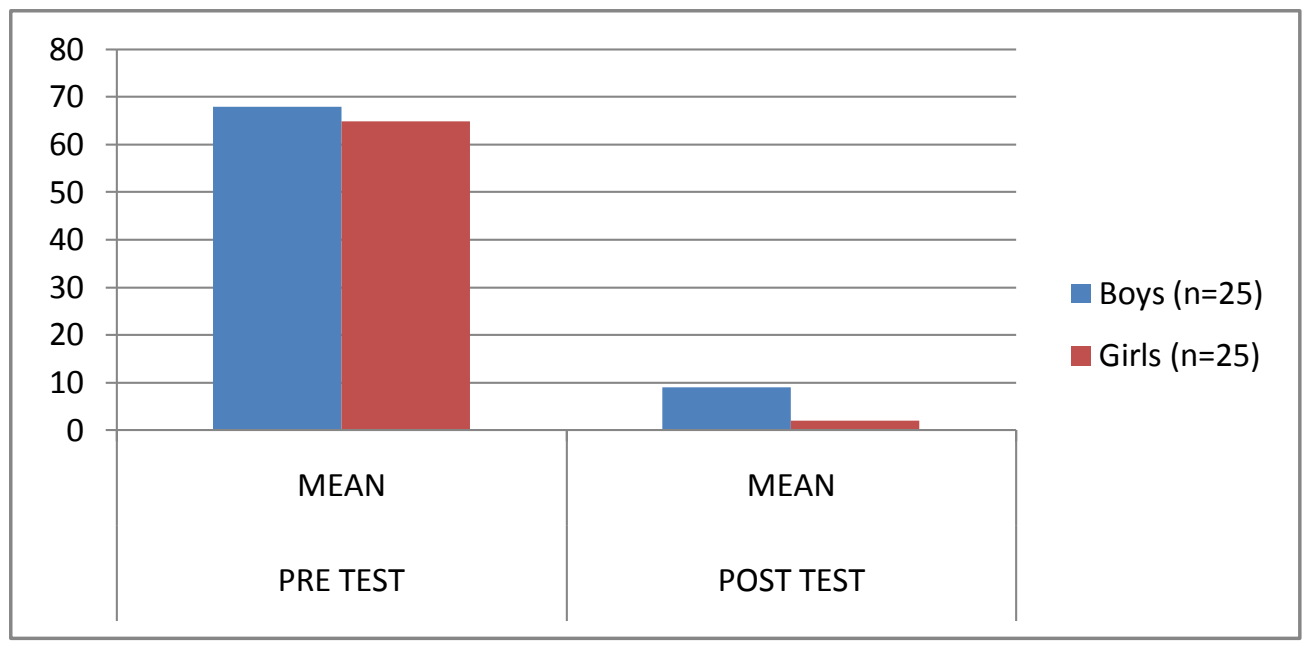

Fig 2: Mean Pre and Posttest Percentile rank of Trait Anxiety of the school students

Table 3 showed that there is extremely significant difference $(\mathrm{P}>0.0001)$ existing between Pretest and Posttest scores of the Trait anxiety. Girls were better $(\mathrm{P}>0.0001)$ than the Boys in managing the anxiety through CBT. CBT is one of the best therapeutic techniques in the management of anxiety among school students.

The follow-up assessment revealed that they could lead an anxiety free life and to a great extent were able to identify their stressors and triggers and were able to apply the coping mechanisms taught to them during the therapy sessions.

\section{SUMMARY AND CONCLUSIONS}

Anxiety affects general well-being and impairs academic performance. It also affects harmony in the family life. Anxiety in personality affects one's confidence and output. Children with anxiety can either become a shy and introverted personality or an aggressive personality. As it is said balance is the most important factor in leading a healthy happy life. Similarly anxiety in a balance proportion acts as a well wisher for the individual. It can encourage and motivate to do well, do better, prepare for an exam or presentation or interview. When in excess it affects the day-to-day life activities of the person and can change the very personality of the individual. High anxiety impairs the academic performance. The present study was undertaken to see the effect of CBT in the management of anxiety.

The following conclusions were drawn from the present study:

1. Cognitive behaviour therapy helps students to overcome anxiety within a shorter span of time

2. CBT Girls are the best in the management of their anxiety

3. CBT helps to overcome anxiety and improve academic performance 
4. In sum, CBT is one of the best therapeutic techniques in the management of anxiety among students. It is more economical and less time consuming method of management of anxiety,

\section{REFERENCES}

Cattell, RB., Eber, HW (1962). Manuals for Forms A and B 16 Personality questionnaire. "The 16 PF". Young adults and adults. USA: Institute of Personality and Ability Testing.

Cattell, RB., Hebert, WE (1962). Supplement of norms for Forms A and B of the Sixteen Personality Factor Questionnaire. "The 16 PF Test”. USA, Illinois: Institute of Personality and Ability Testing

Chandramohan (1991). Computerisation of 16 Personality Factor Test. IAM/Project No. 139/ $1 / 89$.

Chandramohan, V (1998). Application of Behaviour therapy and Ground simulator in the Management of Airsickness. Ph.D., Thesis. Bangalore University.

Christensen, IP., Wagner, HL., Halliday, MS (2006). Instant Notes, Psychology, psychopathology, anxiety disorders. p.269. New York : McGrahill Series.

Kaliappan, KV., Murthy, HSN (1978). A case of tics - behaviour therapy. Proceedings of IV All India Convention of Clinical Psychologist Madras (Abstract)

Rosen J. B, Schulkin, J (1998). "From normal fear to pathological anxiety". Psychol Rev. 105 (2): 325-50. PMID 9577241

Seligman, MEP., Walker, EF., Rosenhan, DL (2001). Abnormal Psychology. (4th ed.) New York: W.W. Norton Company, Inc.

Spielberger, CC (1979). Preliminary Manual for the State- Trait Personality Inventory (STPI). CA: University of Florida

Spielberger, CC., Jacobs, O. Crane, R., Russell, S., Westberry, L., Barker, L, Johnson, E., Knight, J., Marks, E (1979). Preliminary Manual for the State-Trait Personality Inventory (STPI). Tamba: University of South Florida Human Resources Institute 